\title{
Addendum to: Automatically Determining Symmetries of Partial Differential Equations
}

\author{
F. Schwarz, St. Augustin \\ Received September 16, 1985
}

The purpose of this note is to report several improvements of the REDUCE package for determining symmetries of partial differential equations which has been described in [1]. In addition to having speeded up the solution algorithm by a factor 2 to 5 they concern mainly the form in which the results are returned. To obtain a symmetry generator of the finite subgroup in the usual form as shown in equation (4) of ref. [1], one has to assign the value zero to all constants appearing in the $\xi$ 's and $\eta$ 's except one, multiply the result with the corresponding symbol $\frac{\partial}{\partial x_{i}}$ or $\frac{\partial}{\partial u^{\alpha}}$ respectively and add them up. In the present version this is done by the program. In addition the commutator table of the generators of the finite subgroup is given. The equivalence table at the bottom of page 98 has to be extended by the two entries

\begin{tabular}{|c|c|}
\hline Text & Program \\
\hline$\frac{\partial}{\partial x_{i}}$ & DX (I) \\
$\frac{\partial}{\partial u^{\alpha}}$ & DU(ALFA) \\
\hline
\end{tabular}

As an example let us show the result which is obtained for the Navier-Stokes equations. It has to be compared with the output given at the bottom of page 101 of [1].

The symmetry generators

$$
\begin{aligned}
\operatorname{GEN}(1): & =\mathrm{DX}(4) \\
\operatorname{GEN}(2): & =\mathrm{DX}(1) * \mathrm{X}(1) \\
& +\mathrm{DX}(2) * \mathrm{X}(2) \\
& +\mathrm{DX}(3) * \mathrm{X}(3) \\
& +2 * \mathrm{DX}(4) * \mathrm{X}(4) \\
& -\mathrm{DU}(1) * \mathrm{U}(1) \\
& -\mathrm{DU}(2) * \mathrm{U}(2) \\
& -\mathrm{DU}(3) * \mathrm{U}(3) \\
& -2 * \mathrm{DU}(4) * \mathrm{U}(4)
\end{aligned}
$$




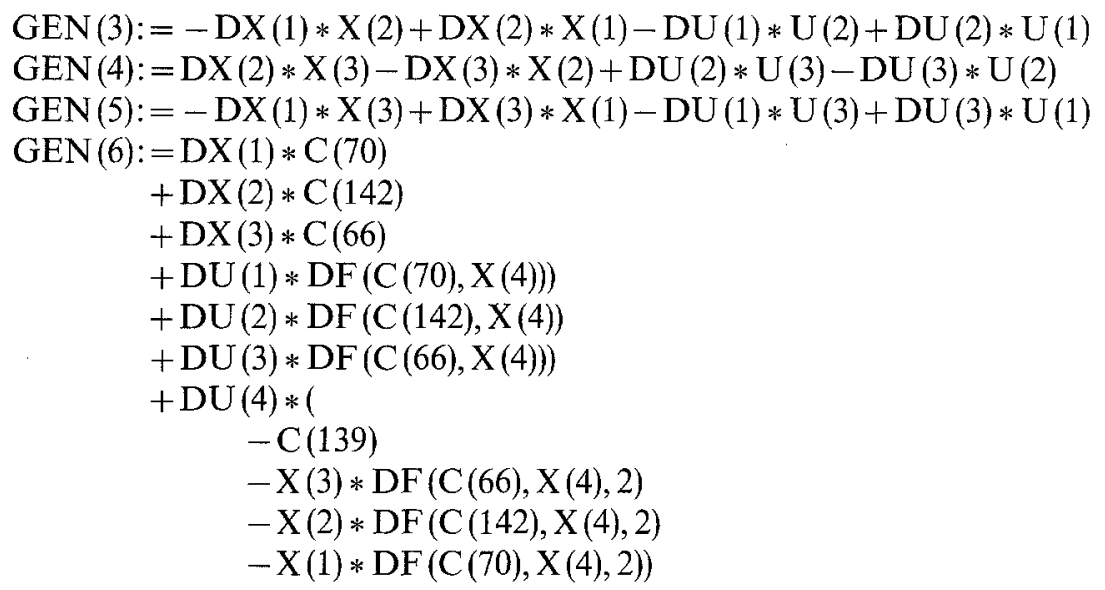

The remaining dependencies

$\mathrm{C}(66)$ depends on $\mathrm{X}(4)$

$C(70)$ depends on $X(4)$

$C(139)$ depends on $\mathrm{X}(4)$

C(142) depends on X(4)

The non vanishing commutators of the finite subgroup

$\operatorname{COMM}(1,2)=2 * \operatorname{DX}(4)$

$\operatorname{COMM}(3,4)=\mathrm{DX}(1) * \mathrm{X}(3)-\mathrm{DX}(3) * \mathrm{X}(1)+\mathrm{DU}(1) * \mathrm{U}(3)-\mathrm{DU}(3) * \mathrm{U}(1)$

$\operatorname{COMM}(3,5)=\mathrm{DX}(2) * \mathrm{X}(3)-\mathrm{DX}(3) * \mathrm{X}(2)+\mathrm{DU}(2) * \mathrm{U}(3)-\mathrm{DU}(3) * \mathrm{U}(2)$

$\operatorname{COMM}(4,5)=\mathrm{DX}(1) * \mathrm{X}(2)-\mathrm{DX}(2) * \mathrm{X}(1)+\mathrm{DU}(1) * \mathrm{U}(2)-\mathrm{DU}(2) * \mathrm{U}(1)$

In this form the structure of the symmetry group is more easily understood. It is immediately seen that GEN(1) corresponds to time translation, GEN(2) to a similarity transformation, GEN(3) to GEN(5) to space rotations. GEN(6) corresponds to an infinite Lie group because it contains 4 arbitrary function of time $t=X$ (4). The package SPDE will be distributed with the next release of REDUCE in April 1986 as announced in [2].

\section{References}

[1] Schwarz, F.: Automatically determining symmetries of partial differential equations. Computing 34, $91-106$ (1985).

[2] REDUCE Newsletter 10, September 1985, page 3.

F. Schwarz

GMD, Institut F 1

Postfach 1240

D-5205 St. Augustin

Federal Republic of Germany 